\title{
Nothing as Practical as a Good Theory? The Theoretical Basis of HIV Prevention Interventions for Young People in Sub-Saharan Africa: A Systematic Review
}

\author{
Kristien Michielsen, ${ }^{1}$ Matthew Chersich, ${ }^{1,2}$ Marleen Temmerman, ${ }^{1}$ \\ Tessa Dooms, ${ }^{2}$ and Ronan Van Rossem ${ }^{3}$ \\ ${ }^{1}$ International Centre for Reproductive Health, Faculty of Medicine and Health Sciences, Ghent University, \\ De Pintelaan 185 P3, 9000 Ghent, Belgium \\ ${ }^{2}$ Centre for Health Policy, School of Public Health, University of the Witwatersrand, Johannesburg 2000, South Africa \\ ${ }^{3}$ Department of Sociology, Faculty of Political and Social Sciences, Ghent University, 9000 Ghent, Belgium
}

Correspondence should be addressed to Kristien Michielsen, kristien.michielsen@ugent.be

Received 29 February 2012; Revised 26 April 2012; Accepted 3 May 2012

Academic Editor: Xiaoming Li

Copyright (C) 2012 Kristien Michielsen et al. This is an open access article distributed under the Creative Commons Attribution License, which permits unrestricted use, distribution, and reproduction in any medium, provided the original work is properly cited.

This paper assesses the extent to which HIV prevention interventions for young people in sub-Saharan Africa are grounded in theory and if theory-based interventions are more effective. Three databases were searched for evaluation studies of HIV prevention interventions for youth. Additional articles were identified on websites of international organisations and through searching references. 34 interventions were included; 25 mentioned the use of theory. Social Cognitive Theory was most prominent $(n=13)$, followed by Health Belief Model $(n=7)$, and Theory of Reasoned Action/Planned Behaviour $(n=6)$. These cognitive behavioural theories assume that cognitions drive sexual behaviour. Reporting on choice and use of theory was low. Only three articles provided information about why a particular theory was selected. Interventions used theory to inform content $(n=13)$, for evaluation purposes $(n=4)$ or both $(n=7)$. No patterns of differential effectiveness could be detected between studies using and not using theory, or according to whether a theory informed content, and/or evaluation. We discuss characteristics of the theories that might account for the limited effectiveness observed, including overreliance on cognitions that likely vary according to type of sexual behaviour and other personal factors, inadequately address interpersonal factors, and failure to account for contextual factors.

\section{Introduction}

With an estimated 2.7 million new infections worldwide in 2010, HIV incidence remains at very high levels [1]. Sub-Saharan Africa, accounting for $70 \%$ of these infections, remains particularly affected. About $40 \%$ of new HIV infections occur in the age group 15 to 24 years [1]. Therefore, targeted prevention programmes for young people are essential in reversing the HIV epidemic [2, 3]. Over the past decades, a considerable number of HIV prevention interventions for young people in sub-Saharan Africa have been developed, implemented, and evaluated. Nevertheless, even though these interventions seem to increase knowledge and encourage positive attitudes, radical changes in sexual behaviour have not occurred $[4,5]$.

Theory is said to be an essential component of successful health promotion interventions $[6,7]$. Behavioural theory can assist to understand the determinants of risky and safe sexual behaviour [8] and hence help to identify underlying principles about how people change their behaviour [9]. Further, it aims to explains why and how behaviours occur and allows us to predict future behaviours by establishing relationships between key variables. Beyond providing constructs, processes and hypotheses for setting up interventions, theories can also provide the basis for testing the effectiveness of interventions [10]. Furthermore, theories 
can serve as a framework for accumulating knowledge [11]. Reviews that assessed the theoretical underpinnings of behavioural interventions for young people worldwide generally claim that a theoretical foundation contributes to effectiveness $[6,12-16]$, although a direct link has not yet been established.

In health promotion research, a large number of theories coexist that aim to understand health-related behaviour and provide tools for behaviour change. The Social Learning/ Cognitive Theory (SCT), Theory of Reasoned Action/ Planned Behaviour (TRA/TPB), and Health Belief Model (HBM) are the most dominant theories, more recently joined by the Stages of Change (SoC) and Social Ecological Model (SEM) [17-21].

The SCT posits that people acquire and maintain particular behavioural patterns through a constant interaction between three factors: environment, personal factors, and behaviour $[22,23]$. Behaviour is not simply the result of the environment and the person, just as the environment is not merely a function of the person and behaviour [17]. The HBM is based on an understanding that a person will take a health-related action if that person believes s/he is susceptible to the condition (perceived susceptibility), that the condition has serious consequences (perceived severity), that taking action would reduce their susceptibility to the condition or its severity (perceived benefits), and that these benefits outweigh the cost of taking action (perceived barriers). Action is taken more easily if the person is exposed to factors that prompt action (cues to action) and is confident in her/his ability to successfully perform an action (selfefficacy) [20, 24-26]. By contrast, the TRA suggests that a person's behaviour is determined by her/his intention to perform the behaviour. This intention is predicated by their attitude toward the specific behaviour and by beliefs about whether individuals who are important to the person approve or disapprove of the behaviour (subjective norm). The TPB includes an additional determinant: the belief $\mathrm{s}$ /he has control over a particular behaviour (perceived behavioural control) $[20,27,28]$. SoC theory argues that, in order to change a behaviour, an individual passes through five stages: precontemplation, contemplation, preparation, action, and maintenance [29]. People at different stages have different informational needs and benefit from interventions tailored to their particular stage [20]. The SEM identifies a number of interacting levels that influence behavior (individual, interpersonal, organizational, community, and public policy). According to this model, behaviours are shaped by the social environment $[20,30]$.

These dominant theories work at various levels and for different purposes. While the HBM and TRA/TPB are explanatory theories operating at the individual level, the SCT and SEM include the interpersonal and environmental levels, respectively. The SoC theory, in turn, is a change theory, not explaining a particular behaviour, but providing a framework for how people alter their behaviour.

With the overarching objective of improving effectiveness of HIV prevention interventions that target young people's sexual behaviour in sub-Saharan Africa, this paper examines the extent to which these interventions are grounded in theory, how these theories are applied and assesses if theorybased interventions are more effective in modifying sexual behaviour than interventions not explicitly grounded in theory.

\section{Methods}

2.1. Study Eligibility, Literature Search, and Data Extraction. We performed a systematic review to locate evaluated interventions that aim to reduce sexual risk behaviour of young people in sub-Saharan Africa. Studies were considered eligible if they reported on the evaluation of an HIV prevention intervention for young people on the subcontinent, had a control group, and were published between January 1990 and March 2012. Further, to be included, studies had to report on the general population of young people (10-25 years) and the intervention needed to aim to prevent HIV transmission by reducing sexual risk taking. Searches were performed in the online databases Medline (PubMed interface), ISI Web of Science, and EBSCOhost. Additional articles were identified on websites of international organisations and through searching references of eligible articles. Data extraction was then done in duplicate by five investigators using a predesigned and pretested extraction sheet. Further details of the search terms, study eligibility, and data extraction are detailed elsewhere [4].

2.2. Study Measures. We extracted data on characteristics of the interventions and theory use. Firstly, whether any theory had been used and, if so, which. Secondly, for what purpose the theory was used. We extracted full-text descriptions of how the theory had been used, which was later recoded into three categories: theory used to inform the intervention (e.g., for curriculum development); theory used to guide evaluation (e.g., to develop indicators); or both. Thirdly, a binary variable was derived, capturing whether an explanation was provided about why this theory was chosen. For the studies not reporting the use of a theory, we looked at the topics dealt with in the interventions and the envisaged interventions' outcomes. This gives us an indication of the underlying theoretical assumptions used in these interventions.

Data were also extracted on the behavioural outcomes of the interventions: condom use (at last sex; consistency and intention), sexual behaviour (primary abstinence; the proportion of sexually active youth; recent sexual intercourse; number of sexual partners and multiple partnerships), and biological outcomes (HIV/STI incidence).

\section{Results}

1073 article titles and/or abstract were screened. After analysis of title and abstract, we reviewed 73 full-text publications. In total, evaluations of 34 studies met the inclusion criteria, reported on in 38 articles. Table 1 sums the main intervention characteristics and study designs. 


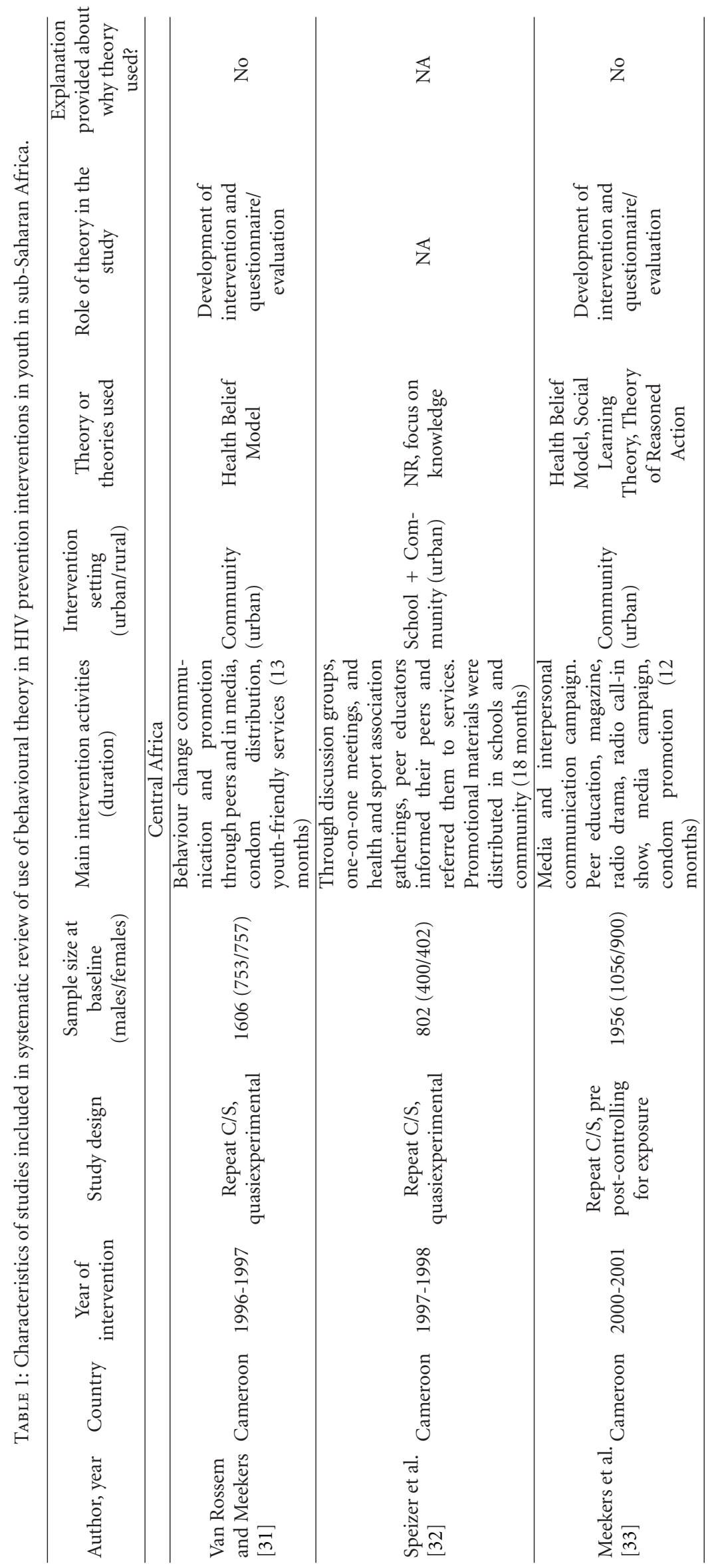




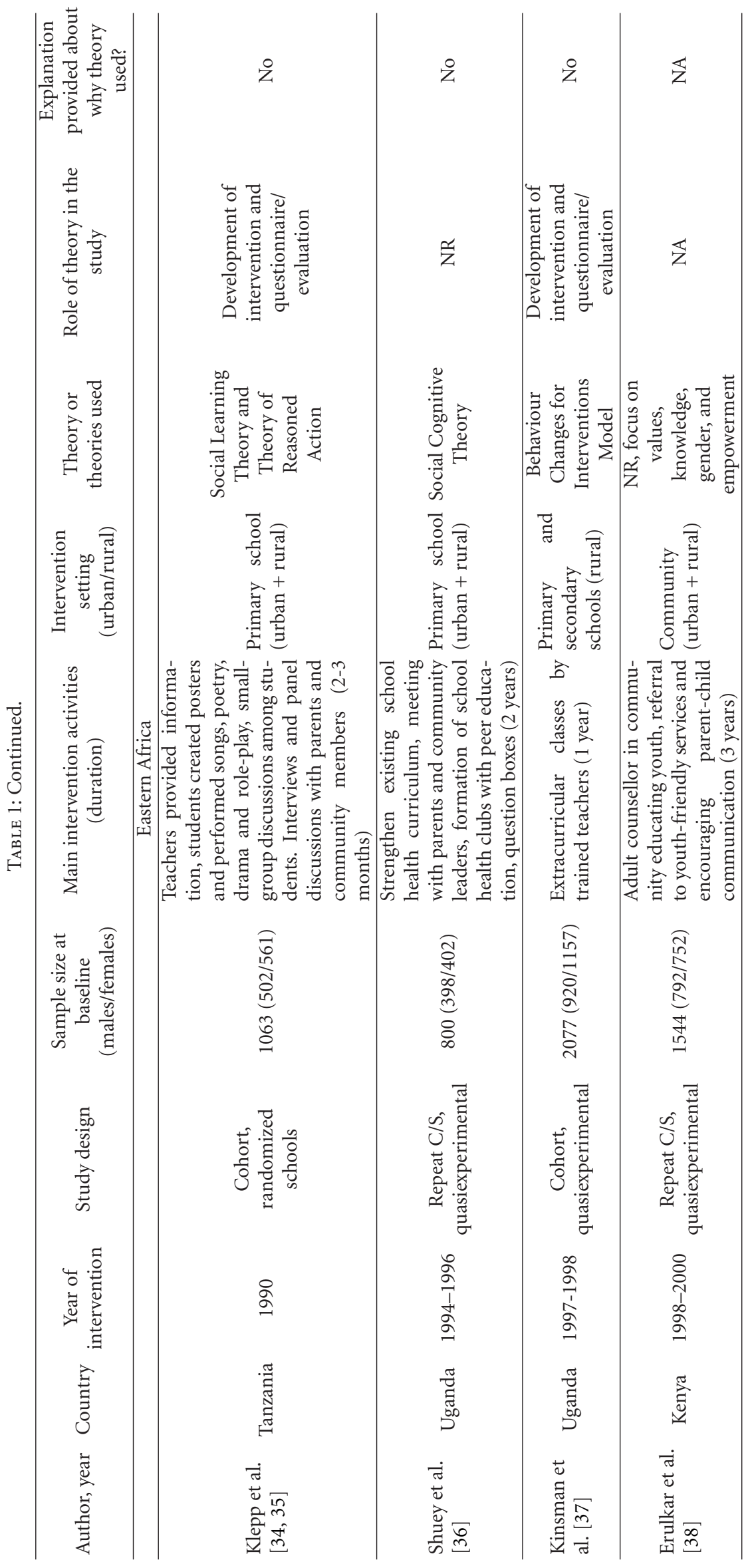




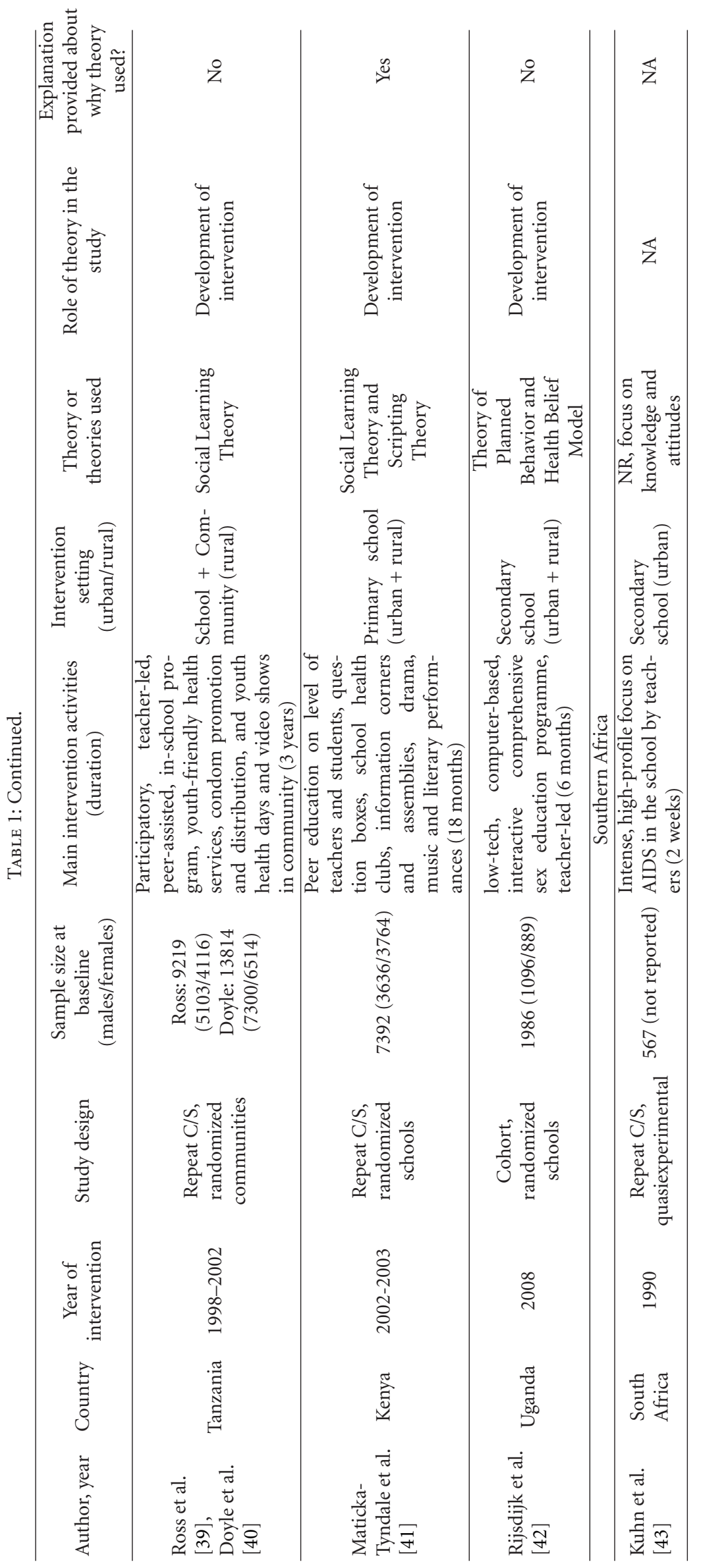




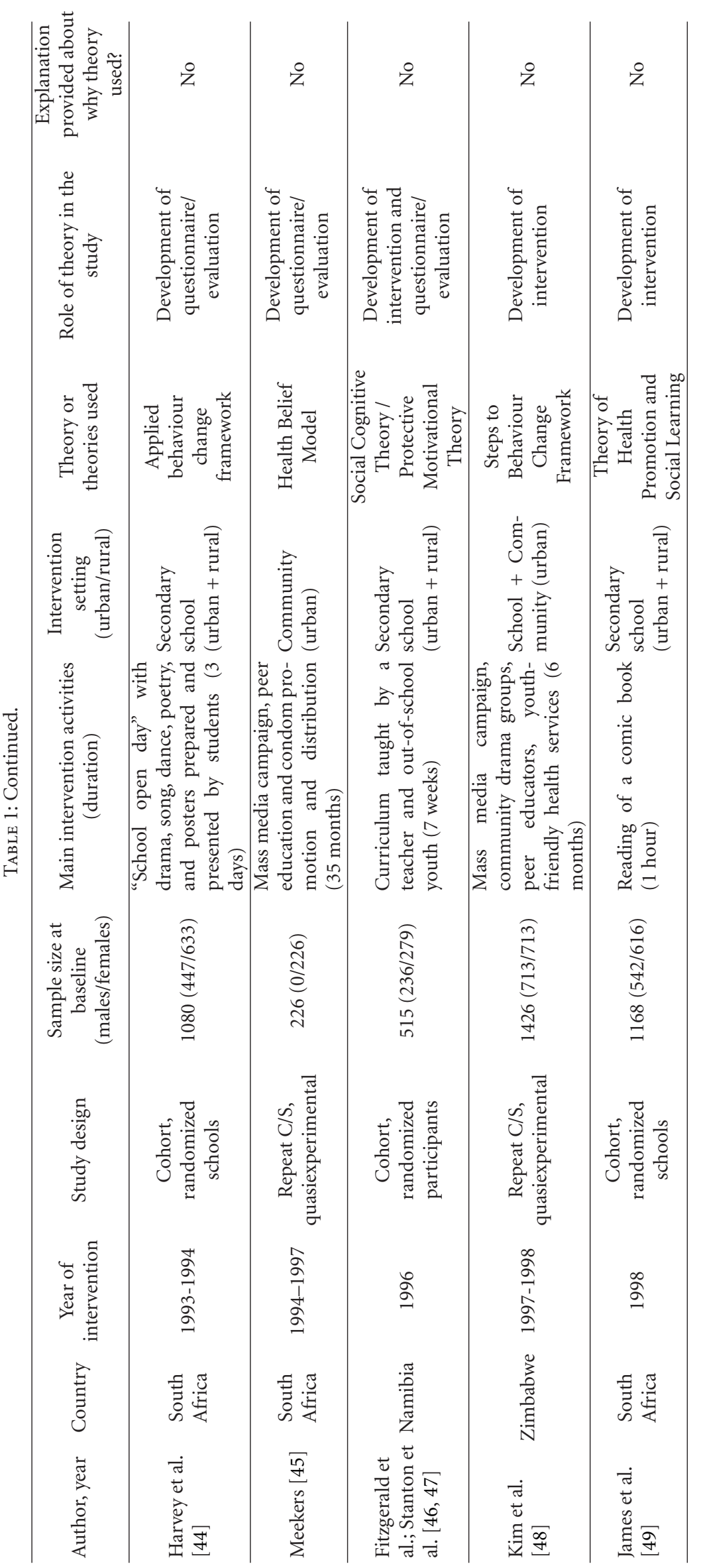




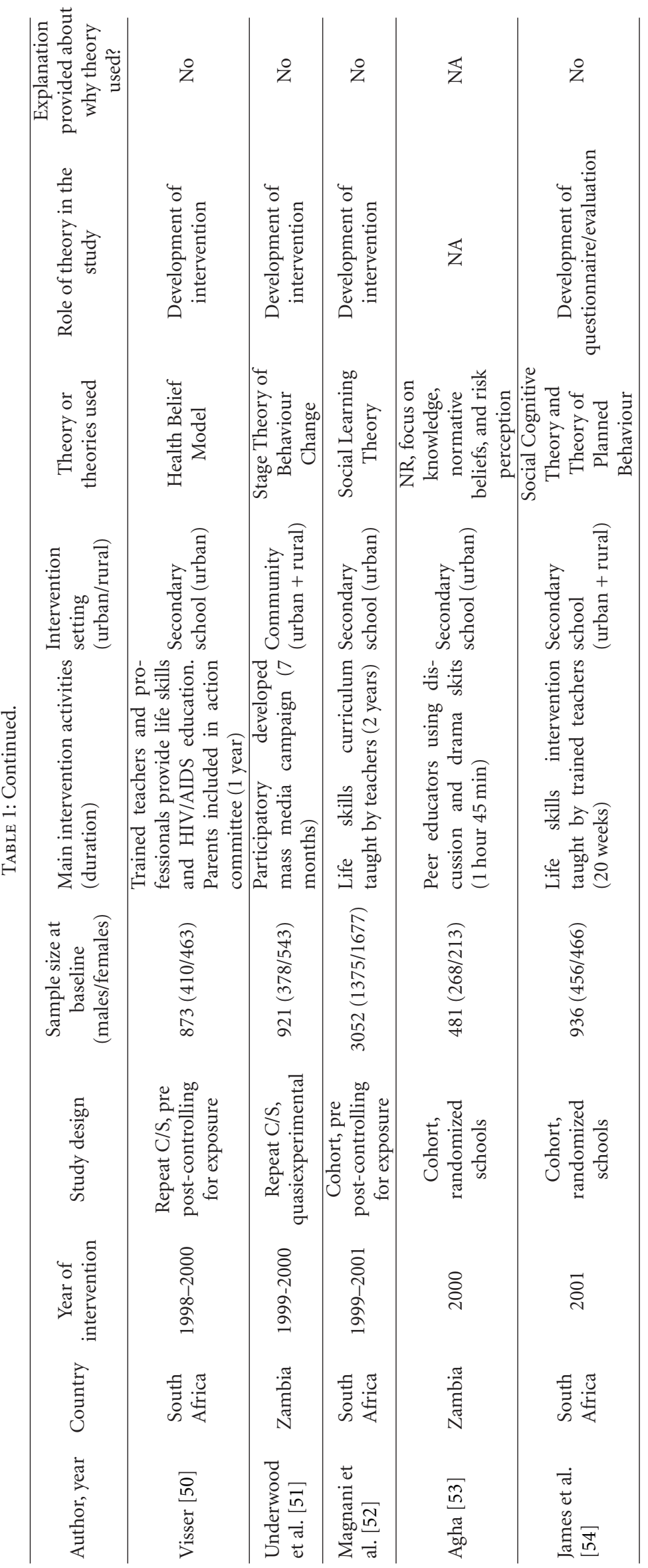




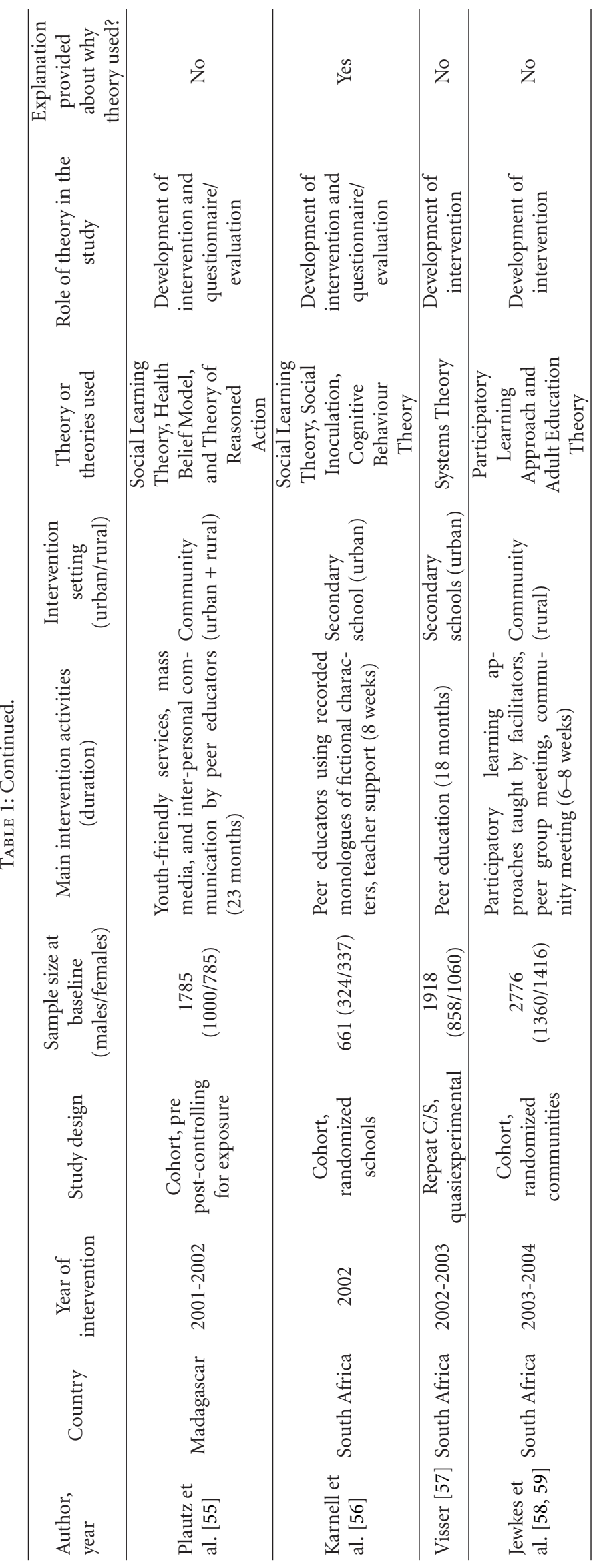




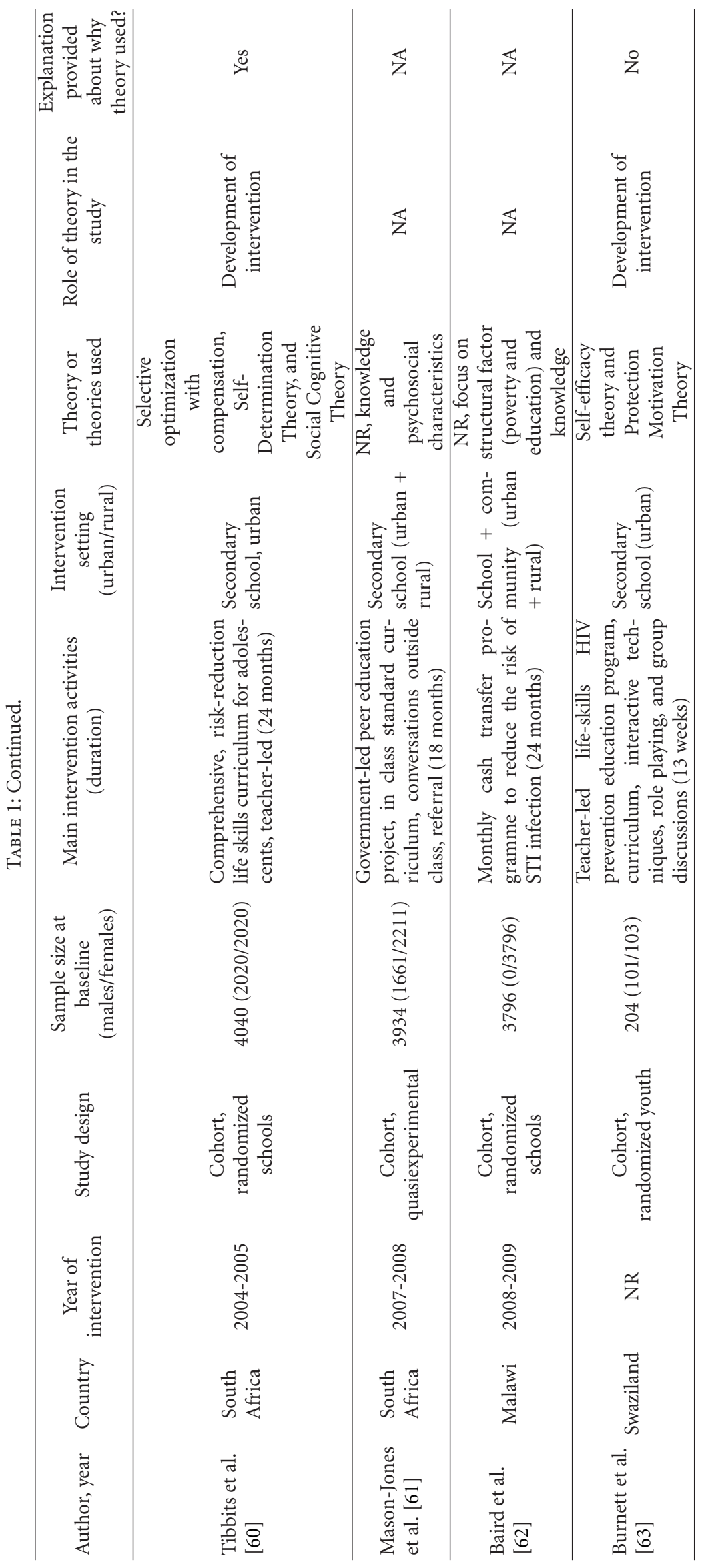




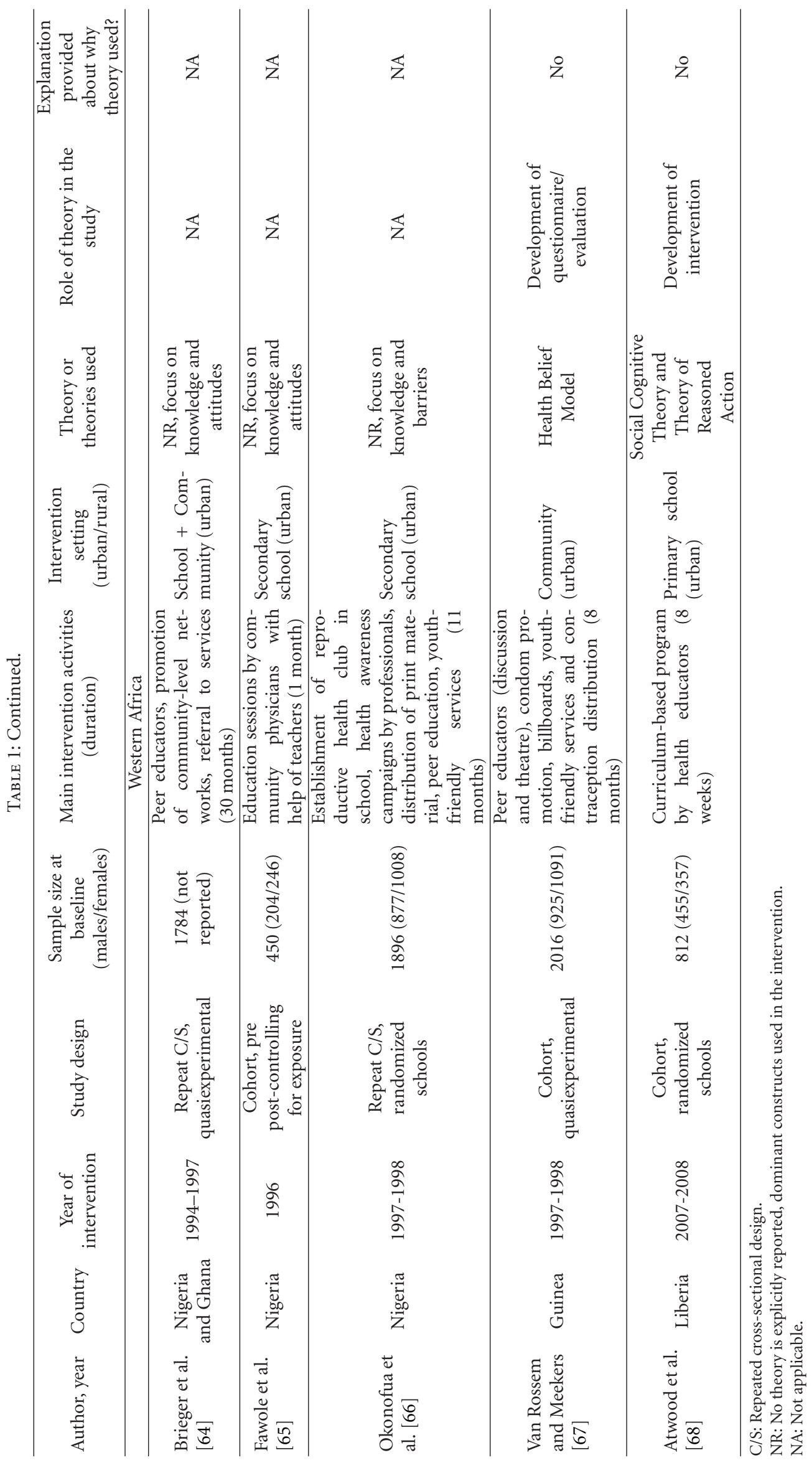


3.1. Theoretical Basis of the Interventions. About three quarters of the studies - 25 of 34 - mentioned having used at least one theory. In total, 19 different theories were mentioned 42 times. Several stated that they had applied two or more theories, with three papers reporting that the intervention design drew on three theories.

Of all the theories mentioned, the SCT was most prominent $(n=13)$. Other theories that were mentioned more than once are the HBM $(n=7)$ and the TRA/TPB $(n=6)$. Four studies mentioned using a behaviour change framework: behaviour changes for interventions model [37], applied behaviour change framework [44], steps to behaviour change framework [48] and stage theory of behaviour change [51]. Assessment of the concepts used in the interventions not explicitly mentioning the use of a theory indicated that they also operated from an assumption that knowledge, attitudes, beliefs, and/or role models determine sexual behaviour. Hence, it seems that most interventions are implicitly or explicitly guided by cognitive behavioural frameworks. The one exception is Baird (2012); this intervention uses an indirect pathway to try to influence HIV incidence, namely, through encouraging girls' school attendance.

Description of the main activities indicates that most interventions use one or a combination of participatory learning techniques, such as drama plays, poetry, songs, club formation, peer education (role modelling), and discussions and debates. This suggests that the learning strategies of most interventions were based on participatory learning approaches.

A small, but considerable proportion of interventions $[32,34-36,38-40,58,62,64]$ go beyond focusing on the individual young person and facilitate community involvement in the interventions. Here, the implicit theoretical assumption is that in order to change the participants' sexual behaviour, the community needs to be involved (cf. SEM).

There is no clear evolution detectable over time in the frequency of use of different theories; of the 20 studies which began in the decade 1990-1999, 14 reported theory use, while 11 of the 14 beginning after 2000 used theory.

3.2. Use of Theory in the Research Projects. Of 25 interventions that mentioned a theory, 7 said that the theory was used to both inform the content of the intervention (e.g., the curriculum) and to inform the evaluation or questionnaire design. In 13 studies, theory was reportedly used only to inform the intervention content, and in 4 only for designing the evaluation or questionnaire. One study mentioning theory use did not specify how this was applied [36]. The SCT was almost exclusively used to inform the intervention. The HBM was mostly used for evaluation purposes, predominately in studies from Population Services International $[31,33,45,55,67]$, as was the TRA/TPB.

Only three articles provided information on why a particular theory was selected $[41,56,60]$. Nine authors limited themselves to a brief explanation of the theory itself $[31,37,42,45,48,50,51,63,67]$. The remainder did not provide any information on theory selection.
3.3. Theory Use and Intervention Effectiveness. Overall, the behavioural outcomes of the 34 studies were markedly heterogeneous, with little reduction in heterogeneity after stratifying by theory use (Table 2). It was not possible to discern any patterns in differential effectiveness between the role of theory in a study, or between studies reporting or not reporting theory use. Nor did we find particular differences in intervention design by theory use.

Four studies reported biological measures of intervention effectiveness [39, 40, 58, 59, 62]. Jewkes succeeded in reducing HSV-2 incidence. Baird's study, not explicitly based on theory, reported a reduced HIV incidence and HSV2 incidence in the intervention group as compared to the control group, but these data were not controlled for baseline prevalence and should be treated with some caution [62]. Since the three other studies reporting biological measures all based their intervention on a theory, it is not possible to compare the effectiveness of theory- and non-theory-based interventions in changing these outcomes.

3.4. Evaluation of the Theory. Four studies refer to their theoretical basis in their conclusions, criticizing the theory, specifically "the theoretical approaches underlying the program have built in shortcomings which could result in the program not having significant impact on the students' behavioural intentions" [69]; "the discrepancies in the findings may be substantiated by the lack of systematic information that was available on the empirical and theoretical underpinnings upon which the KwaZulu-Natal Department of Education's program was based-a finding similar to reports of those educational programs that were not grounded in a theoretical understanding of adolescent sexual behaviour [...]" [54]; "These findings present mixed evidence regarding the relationship between self-efficacy and outcome expectations and HIV protective behaviours among adolescents in Swaziland." [63]; “ТPB has received considerably more support from research for its predictive power of safe sex behaviour than the HBM." [42].

\section{Discussion}

The review found that the majority of HIV prevention interventions targeted at youth in sub-Saharan Africa use theory-based approaches. A wide range of theories have been employed, but three behavioural theories predominate: SCT, HBM, and TRA/TPB. No one theory emerged dominant, as reporting on the choice, use, and specific evaluation of theory was low.

4.1. Comparison with Other Reviews. Broadly, the results are consistent with reviews of HIV risk-reduction interventions elsewhere, though some variation in use of theory can be noted across these reviews. Pedlow and Carey [70] reviewed 23 randomized controlled trials of HIV risk-reduction interventions for adolescents in the United States and found an explicit theoretical rationale in all but one study. Similar to our review, SCT was most common (18/23). Three other theories were used in four or more studies (TRA, HBM, 


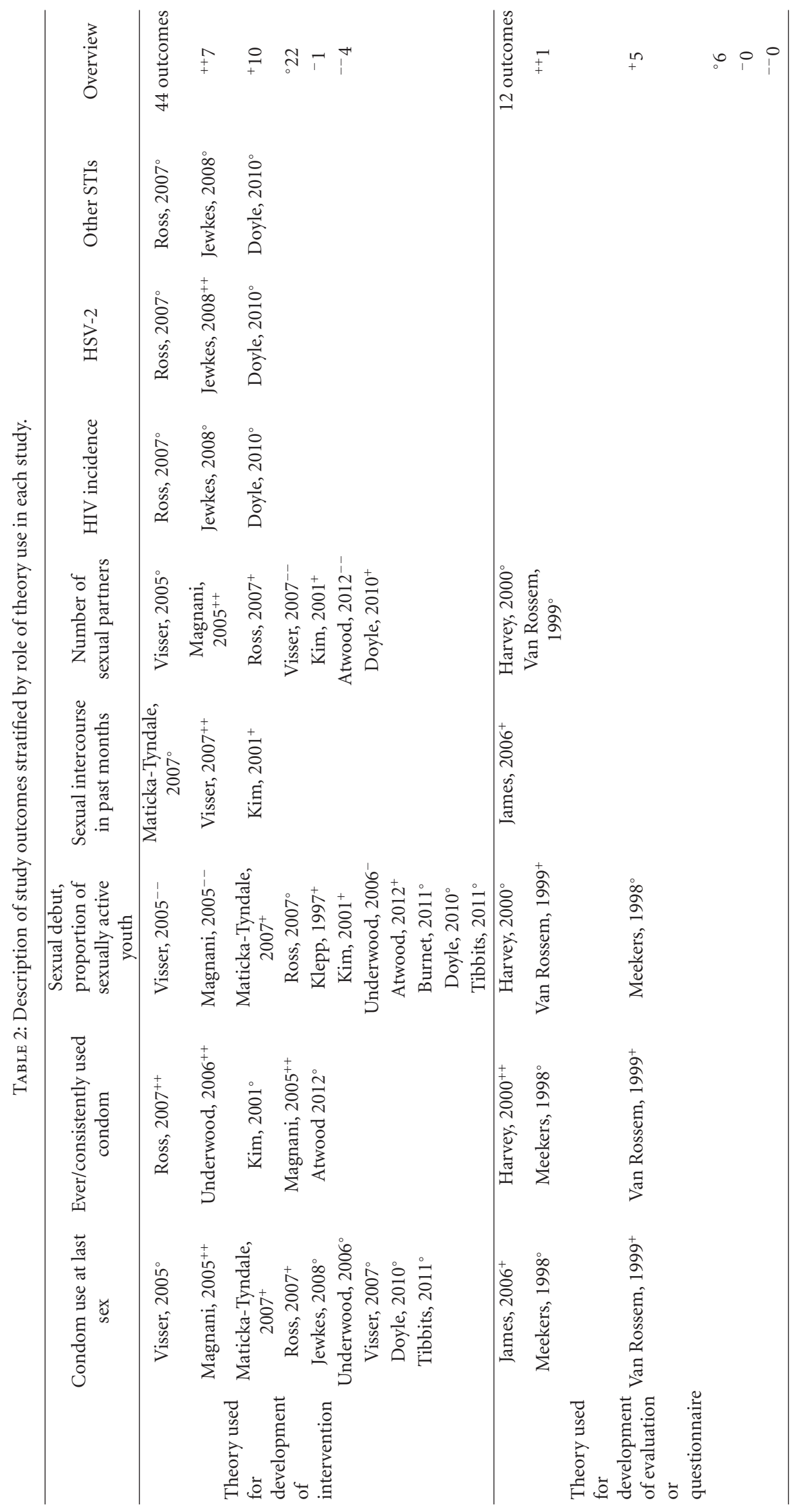




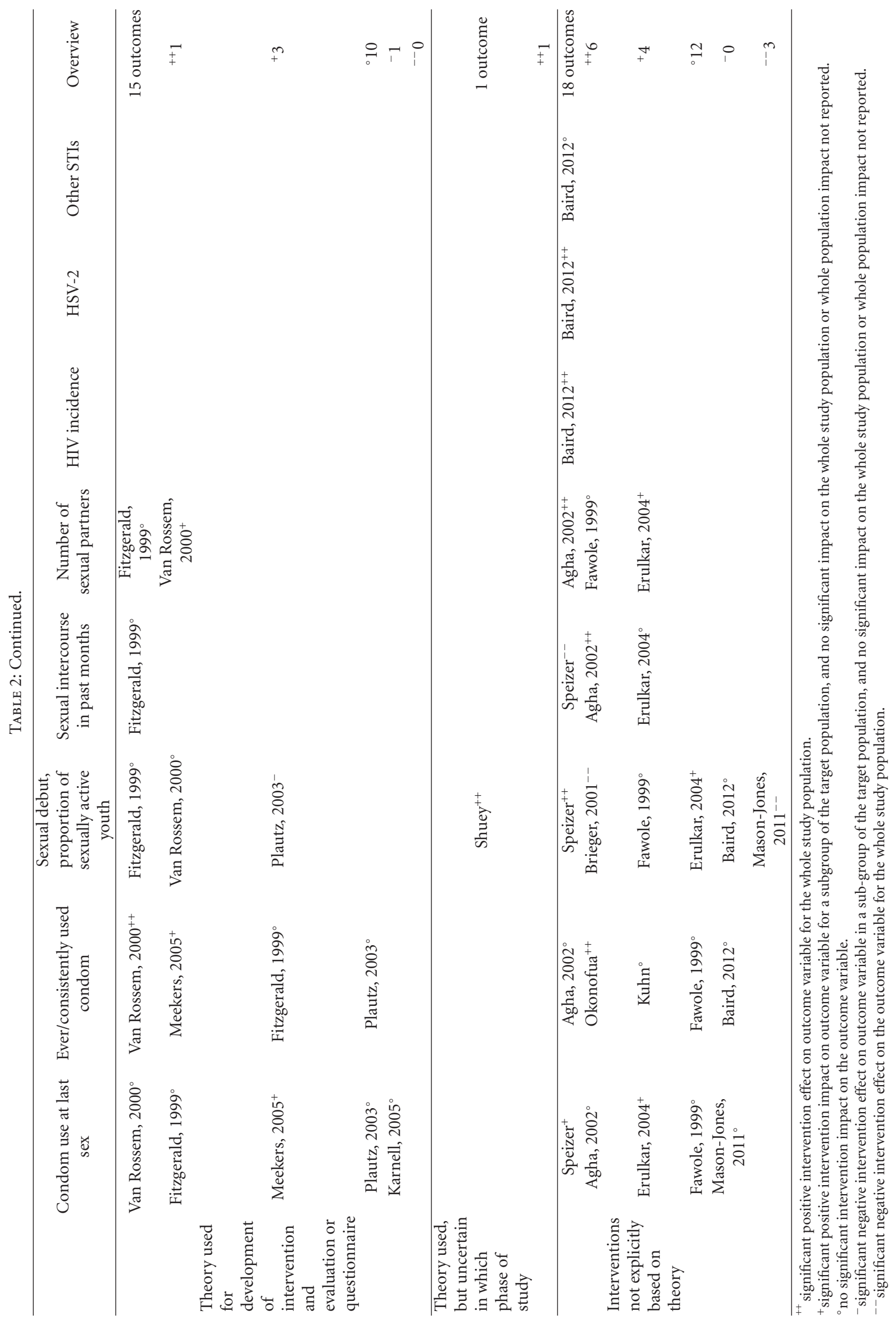


and Information-Motivation-Behavioural Skills Model). A review on the impact of HIV and sex education programs on youth throughout the world [6] found that more than four fifths of the 83 interventions identified one or more theory. SCT formed the basis for more than half (54\%) of these interventions. TRA (19\%), HBM (12\%), TPB (10\%), and the Information-Motivation-Behavioural Skills Model (10\%) were also commonly mentioned. Two other reviews covering HIV, STD, or pregnancy risk-reduction interventions among adolescents in the United States had comparable results, with a similar distribution of theories used $[12,71]$. While several new theories or integrated models have been developed since the outbreak of HIV focussing specifically on sexual health behaviours like condom use $[8,72]$, they are not used in HIV interventions for young people in sub-Saharan Africa.

4.2. Gaps in (the Use of) Theory. By focussing on cognitive constructs of behaviour, the interventions explicitly or implicitly start from the assumption that cognitions influence the person's thinking and decision making, and thus drive sexual behaviour [73]. In the remaining discussion, we will focus on the utility of grounding HIV prevention interventions for young people on a cognitive behavioural framework. We attempt to identify critical areas for attention and improvement on different levels.

Firstly, cognitive behavioural models aim to explain a particular behaviour. The theoretical constructs that influence behavioural decisions may vary, depending on the behaviour in question. This poses marked challenges for HIV prevention interventions, since they generally attempt to influence a wide range of behaviours-for example, increasing condoms use, reducing the number of sexual partners, minimising sexual activity, delaying the onset of sexual debut-which are influenced by different factors. To further complicate matters, sexual decisions may vary depending on the reasons for sexual intercourse (ranging between, e.g., intimacy or desire, external factors, and affect management). These, in turn, are further influenced by gender and psychological characteristics (e.g., depression, self-esteem, and impulsiveness) [74]. Thus, sexual behaviour itself is far from a uniform behaviour, but rather a collection of several relatively distinct behaviours, that can be shaped by different factors in different contexts. While the use of a theoretical framework provides grip in structuring an HIV prevention intervention, the interventionist needs to be very clear about what behaviour they aim to alter and which factors determine this behaviour.

Second, the applicability of cognitive behavioural models to youth sexual behaviours may vary between development stages. For instance, applying cognitive theory to young people with no or limited sexual experience may be difficult. This group may not yet have well-anchored ideas, and consequently their attitudes, norms, and beliefs about safe sexual behaviour may be less clear and stable than for their adult counterparts [70, 73]. Theories used in HIV interventions targeted at youth could be strengthened by accounting for the extent to which individual decision making is supported by one's age, gender, or other personal characteristics.
Third, these theories seem to ignore the fact that sexual intercourse takes place between two persons, within a relationship. Sexual decisions do not depend on the individual, but also on the sexual partner and the type of relationship. Young people might have specific types of partners that may influence sexual decision making. For example, relationships with someone who is much older are risky because it exposes the younger person (mostly girls) to a partner who is more likely to be sexually experienced and hence more likely to be HIV-positive $[75,76]$. Often, these age-disparate relationships are transactional in nature, with money or gifts given in exchange for sexual intercourse [75, 77-81]. Also, young people in same-age relationships might have different types of relationships than adults. They tend to be in what is called by Bastard et al. [82] the "courtship-seduction" phases of relationships, in which the predominant concerns are to "present the best image, win trust, and avoid sources of conflict. These concerns take precedence over that of protecting oneself from the risk of AIDS."

Fourth, while some interventions recognize the importance of involving the community, only the SCT explicitly stresses the influence of contextual and structural factors on an individual's behaviour. Even though the theory states that the social environment is an important determinant of the behaviour, many interventions based on SCT did not attempt to include or influence environmental factors. Most interventions are limited to providing information and teaching skills. TRA/TPB implicitly includes this level by stating that personal attitudes, and norms are influenced by behavioural and normative beliefs in the society, which is useful for tracking varying modes of sexual socialisation. However, this is an indirect effect of the environment on individual behaviour, while still ignoring the broader structural factors that shape sexual behaviour. Many recent studies have demonstrated the contribution of structural factors to young people's vulnerability for HIV [75, 83-85]. These environmental aspects include both distal influences-such as taboos on adolescent sexuality, norms and values, policies, poverty, education as well as more proximate influences. These include families' opinions about adolescent relationships or teachers refusing to talk about condoms. Increased efforts in future studies to account for structural factors at a theoretical level may improve the design of interventions and assist in their evaluation, by understanding the possible barriers between motivation and actual behaviour change.

According to Gielen and Sleet [86], behavioural interventions can be subdivided into three categories, those aimed at intrapersonal factors (e.g., knowledge, skills, and intentions); interpersonal factors (including relational motivations and social desirability); community factors (e.g., culture, gender inequalities, poverty, and violence). We have already argued that the most common theories used in HIV interventions directed to youth do not adequately address interpersonal factors, the failure to account for contextual factors further compounds the difficulty of evaluating interventions and understanding the possible barriers between motivation and actual behaviour change.

Finally, while cognitive behavioural theories of change might be successful in altering cognitions and behavioural 
intentions, they provide insufficient directives on translating this into actual behaviour change. Thus interventions could be regarded as successful in having altered motivations and intentions, even though behavioural change may not result. Similarly, interventions based on the HBM, might increase the perceived severity and susceptibility of a person, and relieve barriers to behaviour change, but in itself, might be insufficient to alter the sexual behaviour. Clearly, motivations or beliefs about behaviour change on a cognitive or rational level need to be accompanied by a clear strategy for introducing a new behaviour [87].

\section{Conclusion}

In the end, it boils down to two key questions: what determines sexual behaviour of young people? And what frameworks are most useful for making sense of and impacting positively on determinants of youth sexual behaviour? Recognizing the complexity and heterogeneity of this particular behaviour, theory can provide help in generalizing key determinants and making them operational. Theories aim to describe determinants and processes that account for or guide behaviour (change) through the rationalization of individual decisions. This aids in understanding human behaviour, and when used appropriately, can provide a solid grounding for program development and evaluation. The strength of theory is to generalize and simplify complex situations. However, in the case of HIV prevention interventions for young people, the dominant theories might oversimplify sexual behaviour. While such cognitive behavioural models can explain the links between intention and behaviour, particularly at an intrapersonal level, they are less able to account for interpersonal and contextual factors related to the complexity of sex, the experience of youth and disparities in social, cultural, and economic realities of youth in subSaharan Africa.

\section{Acknowledgments}

K. Michielsen acknowledges the Research Foundation Flanders (FWO) for financial support. The authors acknowledge Stanley Luchters and Petra De Koker for data extraction.

\section{References}

[1] UNAIDS: UNAIDS World AIDS Day Report 2011, How to get to zero: Faster. Smarter. Better, Geneva, Switzerland, 2011.

[2] T. J. Coates, L. Richter, and C. Caceres, "Behavioural strategies to reduce HIV transmission: how to make them work better," The Lancet, vol. 372, no. 9639, pp. 669-684, 2008.

[3] C. Marston and E. King, "Factors that shape young people's sexual behaviour: a systematic review," The Lancet, vol. 368, no. 9547, pp. 1581-1586, 2006.

[4] K. Michielsen, M. F. Chersich, S. Luchters, P. de Koker, R. van Rossem, and M. Temmerman, "Effectiveness of HIV prevention for youth in sub-Saharan Africa: systematic review and meta-analysis of randomized and nonrandomized trials," AIDS, vol. 24, no. 8, pp. 1193-1202, 2010.
[5] S. M. N. Mavedzenge, A. M. Doyle, and D. A. Ross, "HIV prevention in young people in sub-Saharan Africa: a systematic review," Journal of Adolescent Health, vol. 49, no. 6, pp. 568586, 2011.

[6] D. B. Kirby, B. A. Laris, and L. A. Rolleri, "Sex and HIV education programs: their impact on sexual behaviors of young people throughout the world," Journal of Adolescent Health, vol. 40, no. 3, pp. 206-217, 2007.

[7] J. Green, "The role of theory in evidence-based health promotion practice," Health Education Research, vol. 15, no. 2, pp. 125-129, 2000.

[8] M. Fishbein, "The role of theory in HIV prevention," AIDS Care, vol. 12, no. 3, pp. 273-278, 2000.

[9] Family Health International, Behavior Change-A Summary of Four Major Theories, Family Health International, Arlington, Tex, USA, 2002.

[10] D. R. Rutter and L. Quine, Changing Health Behaviour. Intervention and Research with Social Cognitive Models, Open University Press, Philadelphia, Pa, USA, 2002.

[11] D. C. Des Jarlais, C. Lyles, N. Crepaz, and Group T, "Improving the reporting quality of nonrandomized evaluations of behavioral and public health interventions: the TREND statement," American Journal of Public Health, vol. 94, no. 3, pp. 361-366, 2004.

[12] J. B. Jemmott and L. S. Jemmott, "HIV risk reduction behavioral interventions with heterosexual adolescents," AIDS, vol. 14, supplement 2, pp. S40-S52, 2000.

[13] B. T. Johnson, M. P. Carey, K. L. Marsh, K. D. Levin, and L. A. J. Scott-Sheldon, "Interventions to reduce sexual risk for the human immunodeficiency virus in adolescents, 1985-2000: a research synthesis," Archives of Pediatrics and Adolescent Medicine, vol. 157, no. 4, pp. 381-388, 2003.

[14] J. D. Fisher and W. A. Fisher, "Changing AIDS-risk behavior," Psychological Bulletin, vol. 111, no. 3, pp. 455-474, 1992.

[15] J. A. Kelly and S. C. Kalichman, "Behavioral research in HIV/AIDS primary and secondary prevention: recent advances and future directions," Journal of Consulting and Clinical Psychology, vol. 70, no. 3, pp. 626-639, 2002.

[16] J. P. Moatti and Y. Souteyrand, "Editorial: HIV/AIDS social and behavioural research: past advances and thoughts about the future," Social Science and Medicine, vol. 50, no. 11, pp. 1519-1532, 2000.

[17] K. Glanz, B. K. Rimer, and F. M. Lewis, Health Behavior and Health Education. Theory, Research and Practice, John Wiley \& Sons, San Francisco, Calif, USA, 2002.

[18] K. Glanz and D. B. Bishop, "The role of behavioral science theory in development and implementation of public health interventions," Annual Review of Public Health, vol. 31, pp. 399-418, 2010.

[19] J. E. Painter, C. P. C. Borba, M. Hynes, D. Mays, and K. Glanz, "The use of theory in health behavior research from 2000 to 2005: a systematic review," Annals of Behavioral Medicine, vol. 35, no. 3, pp. 358-362, 2008.

[20] National Cancer Institute, Theory at Glance. A Guide for Health Promotion Practice, National Cancer Institute, Washington, DC, USA, 2005.

[21] K. Glanz, F. M. Lewis, and B. K. Rimers, Health Behavior and Health Education: Theory, Research, and Practice, Jossey-Bass, San Francisco, Calif, USA, 1990.

[22] A. Bandura, "Self-efficacy: toward a unifying theory of behavioral change," Psychological Review, vol. 84, no. 2, pp. 191-215, 1977.

[23] A. Bandura, Self-Efficacy: The Exercise of Control, Freeman, New York, NY, USA, 1997. 
[24] I. M. Rosenstock, V. J. Strecher, and M. H. Becker, "Social learning theory and the Health Belief Model," Health Education Quarterly, vol. 15, no. 2, pp. 175-183, 1988.

[25] I. Rosenstock, "Historical origins of the health belief model," Health Education Quarterly, vol. 2, no. 4, pp. 328-335, 1974.

[26] M. H. Becker, "THe health belief model and personal health behavior," Health Education Quarterly, vol. 2, no. 4, pp. 324508, 1974.

[27] I. Ajzen and B. L. Driver, "Prediction of leisure participation from behavioral, normative, and control beliefs: an application of the theory of planned behavior," Leisure Sciences, vol. 13, no. 3, pp. 185-204, 1991.

[28] I. Ajzen and M. Fishbein, Understanding Attitudes and Predicting Social Behavior, Prentice Hall, Upper Saddle River, NJ, USA, 1980.

[29] J. O. Prochaska and C. C. DiClemente, "Stages and processes of self-change of smoking: toward an integrative model of change," Journal of Consulting and Clinical Psychology, vol. 51, no. 3, pp. 390-395, 1983.

[30] U. Bronfenbrenner, The Ecology of Human Development: Experiments by Nature and Design, Harvard University Press, Cambridge, Mass, USA, 1979.

[31] R. van Rossem and D. Meekers, "An evaluation of the effectiveness of targeted social marketing to promote adolescent and young adult reproductive health in Cameroon," AIDS Education and Prevention, vol. 12, no. 5, pp. 383-404, 2000.

[32] I. S. Speizer, B. O. Tambashe, and S. P. Tegang, "An evaluation of the "Entre Nous Jeunes" peer-educator program for adolescents in Cameroon," Studies in Family Planning, vol. 32, no. 4, pp. 339-351, 2001.

[33] D. Meekers, S. Agha, and M. Klein, "The impact on condom use of the " $100 \%$ Jeune" social marketing program in Cameroon," Journal of Adolescent Health, vol. 36, no. 6, article 530, 2005.

[34] K. I. Klepp, S. S. Ndeki, M. T. Leshabari, P. J. Hannan, and B. A. Lyimo, "AIDS education in Tanzania: promoting risk reduction among primary school children," American Journal of Public Health, vol. 87, no. 12, pp. 1931-1936, 1997.

[35] K. I. Klepp, S. S. Ndeki, A. M. Seha et al., "AIDS education for primary school children in Tanzania: an evaluation study," AIDS, vol. 8, no. 8, pp. 1157-1162, 1994.

[36] D. A. Shuey, B. B. Babishangire, S. Omiat, and H. Bagarukayo, "Increased sexual abstinence among in-school adolescents as a result of school health education in Soroti district, Uganda," Health Education Research, vol. 14, no. 3, pp. 411-419, 1999.

[37] J. Kinsman, J. Nakiyingi, A. Kamali et al., "Evaluation of a comprehensive school-based aids education programme in rural Masaka, Uganda," Health Education Research, vol. 16, no. 1, pp. 85-100, 2001.

[38] A. S. Erulkar, L. I. A. Ettyang, C. Onoka, F. K. Nyagah, and A. Muyonga, "Behavior change evaluation of a culturally consistent reproductive health program for young Kenyans," International Family Planning Perspectives, vol. 30, no. 2, pp. 58-67, 2004.

[39] D. A. Ross, J. Changalucha, A. I. Obasi et al., "Biological and behavioural impact of an adolescent sexual health intervention in Tanzania: a community-randomized trial," AIDS, vol. 21, no. 14, pp. 1943-1955, 2007.

[40] A. M. Doyle, D. A. Ross, K. Maganja et al., "Long-term biological and behavioural impact of an adolescent sexual health intervention in tanzania: follow-up survey of the community-based mema kwa vijana trial," PLoS Medicine, vol. 7, no. 6, Article ID e1000287, 2010.
[41] E. Maticka-Tyndale, J. Wildish, and M. Gichuru, "Quasiexperimental evaluation of a national primary school HIV intervention in Kenya," Evaluation and Program Planning, vol. 30, no. 2, pp. 172-186, 2007.

[42] L. E. Rijsdijk, A. E. Bos, R. A. Ruiter, J. N. Leerlooijer, and B. de Haas, "The world starts with me: a multilevel evaluation of a comprehensive sex education programme targeting adolescents in Uganda," BMC Public Health, vol. 11, article 334, 2011.

[43] L. Kuhn, M. Sternberg, and C. Mathews, "Participation of the school community in AIDS education: an evaluation of a high school programme in South Africa," AIDS Care, vol. 6, no. 2, pp. 161-171, 1994.

[44] B. Harvey, J. Stuart, and T. Swan, "Evaluation of a drama-ineducation programme to increase AIDS awareness in South African high schools: a randomized community intervention trial," International Journal of STD and AIDS, vol. 11, no. 2, pp. 105-111, 2000.

[45] D. Meekers, The Effectiveness of Targeted Social Marketing to Promote Adolescent Reproductive Health: the Case of Soweto, South Africa, Population Services International Working Paper, no. 16, 1998.

[46] A. M. Fitzgerald, B. F. Stanton, N. Terreri et al., "Use of Western-based HIV risk-reduction interventions targeting adolescents in an african setting," Journal of Adolescent Health, vol. 25, no. 1, pp. 52-61, 1999.

[47] B. F. Stanton, X. Li, J. Kahihuata et al., "Increased protected sex and abstinence among Namibian youth following a HIV riskreduction intervention: a randomized, longitudinal study," AIDS, vol. 12, no. 18, pp. 2473-2480, 1998.

[48] Y. M. Kim, A. Kols, R. Nyakauru, C. Marangwanda, and P. Chibatamoto, "Promoting sexual responsibility among young people in Zimbabwe," International Family Planning Perspectives, vol. 27, no. 1, pp. 11-19, 2001.

[49] S. James, P. S. Reddy, R. A. C. Ruiter et al., "The effects of a systematically developed photo-novella on knowledge, attitudes, communication and behavioural intentions with respect to sexually transmitted infections among secondary school learners in South Africa," Health Promotion International, vol. 20, no. 2, pp. 157-165, 2005.

[50] M. J. Visser, "Life skills training as HIV/AIDS preventive strategy in secondary schools: evaluation of a largescale implementation process," Journal of Social Aspects of HIV/AIDS Research Alliance, vol. 2, no. 1, pp. 203-216, 2005.

[51] C. Underwood, H. Hachonda, E. Serlemitsos, and U. BharathKumar, "Reducing the risk of HIV transmission among adolescents in Zambia: psychosocial and behavioral correlates of viewing a risk-reduction media campaign," Journal of Adolescent Health, vol. 38, no. 1, pp. 55.e1-55.e13, 2006.

[52] R. Magnani, K. MacIntyre, A. M. Karim et al., "The impact of life skills education on adolescent sexual risk behaviors in KwaZulu-Natal, South Africa," Journal of Adolescent Health, vol. 36, no. 4, pp. 289-304, 2005.

[53] S. Agha, "An evaluation of the effectiveness of a peer sexual health intervention among secondary-school students in Zambia," AIDS Education and Prevention, vol. 14, no. 4, pp. 269-281, 2002.

[54] S. James, P. Reddy, R. A. C. Ruiter, A. McCauley, and B. van den Borne, "The impact of an HIV and AIDS life skills program on secondary school students in Kwazulu-Natal, South Africa," AIDS Education and Prevention, vol. 18, no. 4, pp. 281-294, 2006.

[55] A. Plautz, D. Meekers, and J. Neukom, The Impact of the Madagascar TOP R,seau Social Marketing Program on 
Sexual Behavior and Use of Reproductive Health Services, PSI Research Division Working Paper no. 57, 2003.

[56] A. P. Karnell, P. K. Cupp, R. S. Zimmerman, S. Feist-Price, and T. Bennie, "Efficacy of an American alcohol and HIV prevention curriculum adapted for use in South Africa: results of a pilot study in five township schools," AIDS Education and Prevention, vol. 18, no. 4, pp. 295-310, 2006.

[57] M. J. Visser, "HIV/AIDS prevention through peer education and support in secondary schools in South Africa," Journal of Social Aspects of HIV/AIDS Research Alliance, vol. 4, no. 3, pp. 678-694, 2007.

[58] R. Jewkes, M. Nduna, J. Levin et al., "Impact of stepping stones on incidence of HIV and HSV-2 and sexual behaviour in rural South Africa: cluster randomised controlled trial," The British Medical Journal, vol. 337, no. 7666, pp. 391-395, 2008.

[59] R. Jewkes, M. Nduna, J. Levin et al., "A cluster randomizedcontrolled trial to determine the effectiveness of stepping stones in preventing HIV infections and promoting safer sexual behaviour amongst youth in the rural Eastern Cape, South Africa: trial design, methods and baseline findings," Tropical Medicine and International Health, vol. 11, no. 1, pp. 3-16, 2006.

[60] M. K. Tibbits, E. A. Smith, L. L. Caldwell, and A. J. Flisher, "Impact of HealthWise South Africa on polydrug use and high-risk sexual behavior," Health Education Research, vol. 26, no. 4, pp. 653-663, 2011.

[61] A. J. Mason-Jones, C. Mathews, and A. J. Flisher, "Can peer education make a difference? Evaluation of a South African adolescent peer education program to promote sexual and reproductive health," AIDS and Behavior, vol. 15, no. 8, pp. 1605-1611, 2011.

[62] S. J. Baird, R. S. Garfein, C. T. McIntosh, and B. Ozler, "Effect of a cash transfer programme for schooling on prevalence of HIV and herpes simplex type 2 in Malawi: a cluster randomised trial," The Lancet, vol. 379, no. 9823, pp. 13201329, 2012.

[63] S. M. Burnett, M. R. Weaver, P. N. Mody-Pan, L. A. Reynolds Thomas, and C. M. Mar, "Evaluation of an intervention to increase human immunodeficiency virus testing among youth in Manzini, Swaziland: a randomized control trial," Journal of Adolescent Health, vol. 48, no. 5, pp. 507-513, 2011.

[64] W. R. Brieger, G. E. Delano, C. G. Lane, O. Oladepo, and K. A. Oyediran, "West African youth initiative: outcome of a reproductive health education program," Journal of Adolescent Health, vol. 29, no. 6, pp. 436-446, 2001.

[65] I. O. Fawole, M. C. Asuzu, S. O. Oduntan, and W. R. Brieger, "A school-based AIDS education programme for secondary school students in Nigeria: a review of effectiveness," Health Education Research, vol. 14, no. 5, pp. 675-683, 1999.

[66] F. E. Okonofua, P. Coplan, S. Collins et al., "Impact of an intervention to improve treatment-seeking behavior and prevent sexually transmitted diseases among Nigerian youths," International Journal of Infectious Diseases, vol. 7, no. 1, pp. 6173, 2003.

[67] R. van Rossem and D. Meekers, An evaluation of the Effectiveness of Targeted Social Marketing to Promote Adolescent Reproductive Health in Guinea, PSI Research Division Working Paper no. 23, 1999.

[68] K. A. Atwood, S. B. Kennedy, S. Shamblen et al., "Impact of school-based HIV prevention program in post-conflict Liberia," AIDS Education and Prevention, vol. 24, no. 1, pp. 6877, 2012.
[69] M. Visser, "Evaluation of the first AIDS kit, the AIDS and lifestyle education programme for teenagers," South African Journal of Psychology, vol. 26, no. 2, pp. 103-113, 1996.

[70] C. T. Pedlow and M. P. Carey, "HIV sexual risk-reduction interventions for youth: a review and methodological critique of randomized controlled trials," Behavior Modification, vol. 27, no. 2, pp. 135-190, 2003.

[71] L. Robin, P. Dittus, D. Whitaker et al., "Behavioral interventions to reduce incidence of HIV, STD, and pregnancy among adolescents: a decade in review," Journal of Adolescent Health, vol. 34, no. 1, pp. 3-26, 2004.

[72] D. Kasprzyk, D. E. Montano, and M. Fishbein, "Application of an integrated behavioral model to predict condom use: a prospective study among high HIV risk groups," Journal of Applied Social Psychology, vol. 28, no. 17, pp. 1557-1583, 1998.

[73] J. de Wit, L. Breeman, and L. Woertman, "Hoe beredeneerd is seksueel gedrag van jongeren?" Tijdschrift voor Sociologie, vol. 29, no. 3, pp. 125-131, 2005.

[74] L. H. Dawson, M. C. Shih, C. de Moor, and L. Shrier, "Reasons why adolescents and young adults have sex: associations with psychological characteristics and sexual behavior," Journal of Sex Research, vol. 45, no. 3, pp. 225-232, 2008.

[75] C. Underwood, J. Skinner, N. Osman, and H. Schwandt, "Structural determinants of adolescent girls' vulnerability to HIV: views from community members in Botswana, Malawi, and Mozambique," Social Science and Medicine, vol. 73, no. 2, pp. 343-350, 2011.

[76] S. Leclerc-Madlala, "Age-disparate and intergenerational sex in southern Africa: the dynamics of hypervulnerability," AIDS, vol. 22, supplement 4, pp. S17-S25, 2008.

[77] K. Hawkins, N. Price, and F. Mussa, "Milking the cow: young women's construction of identity and risk in age-disparate transactional sexual relationships in Maputo, Mozambique," Global Public Health, vol. 4, no. 2, pp. 169-182, 2009.

[78] M. Hunter, "The materiality of everyday sex: thinking beyond 'prostitution," African Studies, vol. 61, no. 1, pp. 99-120, 2002.

[79] M. Silberschmidt and V. Rasch, "Adolescent girls, illegal abortions and "sugar-daddies" in Dar es Salaam: vulnerable victims and active social agents," Social Science and Medicine, vol. 52, no. 12, pp. 1815-1826, 2001.

[80] J. Wamoyi, A. Fenwick, M. Urassa, B. Zaba, and W. Stones, "'Women's bodies are shops': beliefs about transactional ex and implications for understanding gender power and HIV prevention in Tanzania," Archives of Sexual Behavior, vol. 40, no. 1, pp. 5-15, 2011.

[81] J. Wamoyi, D. Wight, M. Plummer, G. H. Mshana, and D. Ross, "Transactional sex amongst young people in rural northern Tanzania: an ethnography of young women's motivations and negotiation," Reproductive Health, vol. 7, no. 1, article 2, 2010.

[82] B. Bastard, L. Cardia-Vonèche, D. Peto, and L. van Campenhoudt, "Relationships between sexual partners and ways of adapting to the risk of AIDS: landmarks for a relationshiporiented conceptual framework," in Sexual Interactions and HIV Risk New Conceptual Perspectives in European Research, L. van Campenhoudt, M. Cohen, G. Guizzardi, and D. Hausser, Eds., Taylor \& Francis, London, UK, 1997.

[83] E. Sumartojo, "Structural factors in HIV prevention: concepts, examples, and implications for research," AIDS, vol. 14, supplement 1, pp. S3-S10, 2000.

[84] G. R. Gupta, J. O. Parkhurst, J. A. Ogden, P. Aggleton, and A. Mahal, "Structural approaches to HIV prevention," The Lancet, vol. 372, no. 9640, pp. 764-775, 2008. 
[85] A. Harrison, M. L. Newell, J. Imrie, and G. Hoddinott, "HIV prevention for South African youth: which interventions work? A systematic review of current evidence," BMC Public Health, vol. 10, article 102, 2010.

[86] A. C. Gielen and D. Sleet, "Application of behavior-change theories and methods to injury prevention," Epidemiologic Reviews, vol. 25, pp. 65-76, 2003.

[87] A. Baban and C. Crciun, "Changing health-risk behaviors: a review of theory and evidence-based interventions in health psychology," Journal of Cognitive and Behavioral Psychotherapies, vol. 7, no. 1, pp. 45-67, 2007. 


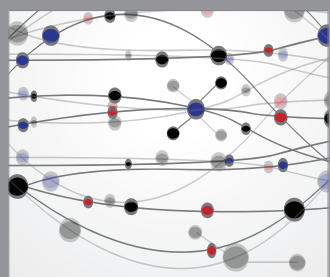

The Scientific World Journal
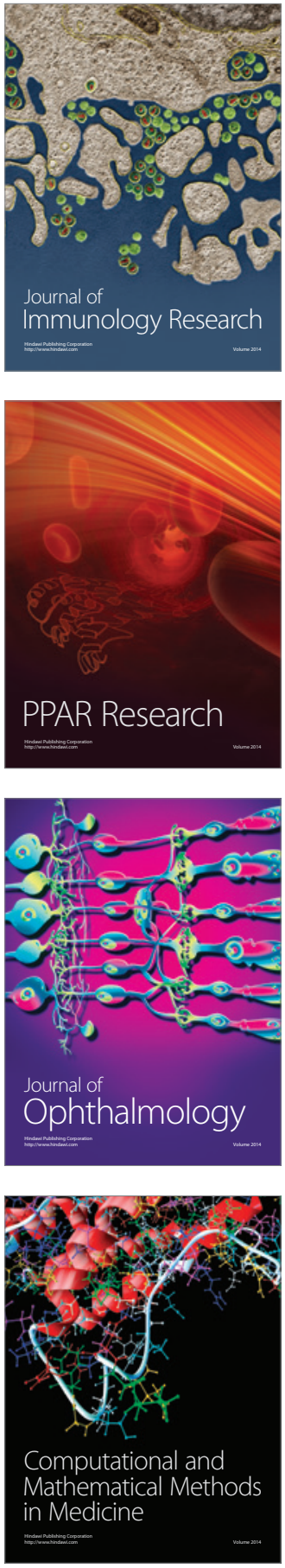

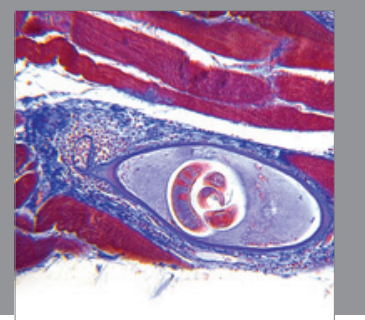

Gastroenterology

Research and Practice
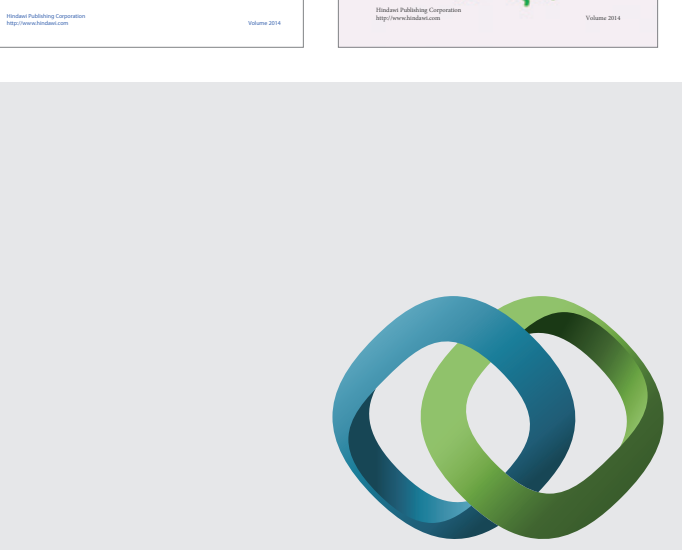

\section{Hindawi}

Submit your manuscripts at

http://www.hindawi.com
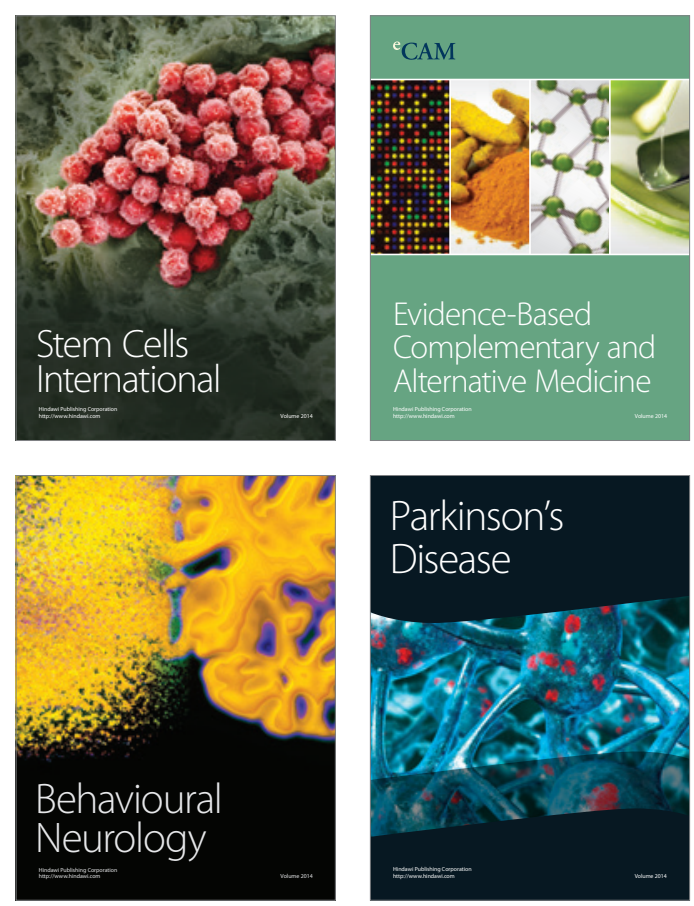

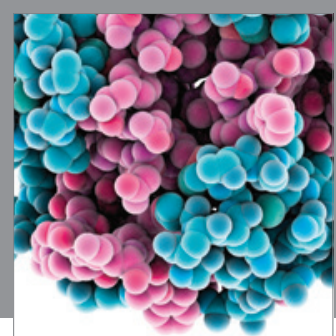

Journal of
Diabetes Research

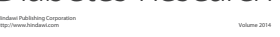

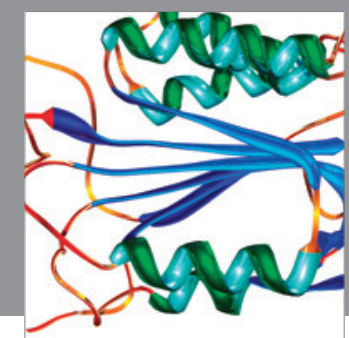

Disease Markers
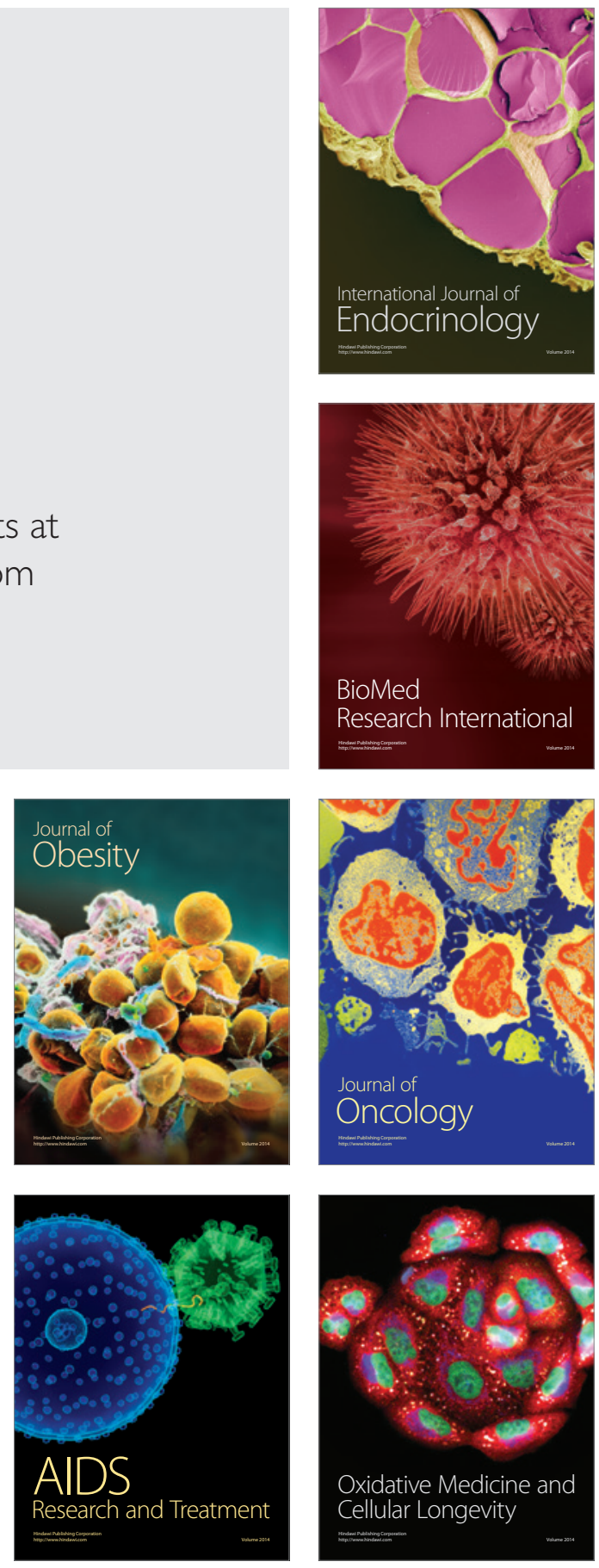